\title{
MÍMESIS, A FONTE: ENTRE O TAMPO DA EDUCAÇÃO E O VÉU DA ARTE
}

\author{
Abah Andrade
}

\begin{abstract}
Resumo:
O presente trabalho, concebido no enclave entre uma filosofia da técnica e a preocupação com um projeto de educação menos comprometido com as forças tradicionais do princípio de identidade, visa estudar o fenômeno da mímesis a fim de concebê-lo como uma espécie de "fonte" de onde pode jorrar tanto a arte quanto a educação. Começa-se por um questionamento do conceito herdado de "realidade"; estuda as concepções de Platão e Aristóteles acerca da mímesis, sugere um conceito de mímesis como "imaginação primeira" ou nexo entre a arte e a natureza, até vir a se dedicar a uma meditação mais atenta à feição própria desse "nexo", que, originário, só pode ser algo como um não-nexo de onde se pode haurir todas as conexões passíveis de virem a ser feitas entre arte e natureza. Isto é, nesse texto tocamos, quiçá, pela primeira vez naquele conceito que viria a ser central em nosso pensamento, e que aqui somente alusivamente o designamos pelo termo "divino", compreendido não como realidade extra-humana ou transcendente, mas como elemento próprio - imanente - do ser humano.
\end{abstract}

Palavras-chave: Mímesis. Arte. Educação. Realidade. Imaginação primeira.

\section{MIMESIS, THE SOURCE: BETWEEN THE COVER OF EDUCATION AND THE VEIL OF ART}

\begin{abstract}
:
The present work, conceived between a philosophy of technique and the education as a project without compromise to the traditional forces of the identity principle, aims to study the phenomenon of mimesis in order to conceive it as a kind of "source" from which both art and education can flow. It begins with a questioning of the inherited concept of 'reality'; studying Plato and Aristotle's conceptions of mimesis, he suggests a concept of mimesis as a 'first imagination' or nexus between art and nature, until he devotes himself to a meditation more attentive to the 'nexus', which, which, originating, can only be something like a nexus from which to draw all the connections that could be made between art and nature. That is, in this text we may touch, perhaps, for the first time in that concept that would become central to our thinking, and which we here only refer to it by the term "divine", understood not as an extrahuman or transcendent reality, but as its own element - immanent - of the human being.
\end{abstract}

Keywords: Mimesis. Art. Education. Reality. First imagination.

A tarefa de articular técnica (palavra de origem grega que remete ao ato de engendrar e, notadamente, engendrar um filho, um rebento) e educação (que não deixa de ser uma arte de produzir, a partir de uma criança, um adulto) convida-nos, salvo melhor juízo, a começar por pensar o exercício da mímesis, como eixo ou fonte dessas duas

1 Pós-Doutorado em Filosofia pela UFSC; Doutorado e Mestrado em Filosofia pela USP e Graduação em Filosofia pela UFPB; professor titular da Universidade Federal da Paraíba. E-mail: andradesimples@gmail.com. 
atividades: criar e educar. Salvo engano, ao menos numa perspectiva didática, de longe o melhor texto indireto dentre os disponíveis entre nós para iniciar-nos no estudo da mímesis é, sem dúvida, o ensaio Do conceito de mímesis, da professora Jeanne-Marie Gagnebin. Sustenta-se esta asserção no fato de que, interessada em apresentar o estado da questão em Theodor Adorno e Walter Benjamin, ela o faz de um modo a criar um contraste instrutivo com a dissonância entre esses pensadores e a clássica (embora nem sempre liminarmente justificável) contraposição de Platão e Aristóteles. Assim, esse texto mostra como a mímesis, em Platão, é drasticamente recusada; como Aristóteles, por sua vez, repõe-na em cena com toda a sua dignidade, e como este jogo de recusa ("rejeição") e reposição ("reabilitação") se repete, com maior alcance, em Adorno e Benjamin. Todavia, malgrado escreva J.-M. Gagnebin no início de seu texto seja sua proposta "apresentar sucintamente um conceito essencial" (GAGNEBIN, 1997, p. 81), justamente o conceito de mímesis, essa apresentação sofre de uma limitação notável, já que ela entra de chofre na cena platônica de A República, sem antes cuidar de oferecer um tratamento minimamente filológico, ou mesmo lexicográfico, para essa palavra, nem sempre imediatamente familiar para todos: mímesis.

Desse modo, é preciso pagar nossa dívida para com a tradição e, mesmo dizendo de partida não seja nem possa ser a mímesis reduzida à ideia comum de "imitação" como cópia, foi, contudo, por meio dessa ideia de imitação que chegamos à palavra grega "mímesis", através de sua tradução por imitatio devida aos autores latinos. Ou seja, o lugar comum (tão certo quanto errôneo, como todo lugar comum) de que a obra literária em particular e a obra de arte em geral são "imitações" da natureza ou do mundo social (errado por se satisfazer muito rapidamente com a noção de duplicação desnecessária ou meramente habilidosa de algo real preexistente, mas correto porque pressupõe desde já a correlação de algum modo efetiva entre uma obra de arte e um mundo qualquer, natural ou social), esse lugar comum não deve ser simplesmente jogado fora, mas deve servir como horizonte inicial de semelhança, isto é, deve atender a expectativa geral do homem comum, para em seguida ser contraposto a um conceito diferente de mímesis, como já veremos ao fazer referência mais direta a Luiz Costa Lima, um conceito que queira e possa se

\begin{tabular}{|l|l|l|l|l|}
\hline Qovista 2 ialectus & Ano 9 & n. 17 & Maio - Agosto 2020 & p.137-151 \\
\hline
\end{tabular}


apresentar como um fenômeno para além da mera imitação, e assim poder tornar-se mais inteligível, digamos melhor, mais passível de ser compreendido estritamente, rendendo um conhecimento novo a respeito da palavra anteriormente posta como evidente. Com feito, de onde vem que, pelo menos uma vez, alguém tenha podido acreditar na correção dessa tomada da mímesis como imitativo no contraponto entre um artefato e uma realidade?

A realidade, do Renascimento da cultura clássica grega pra frente e, sobretudo, depois do Classicismo, sempre fora tomada como o substrato do perceptível. Esta concepção - sabe-se - está na base do uso da perspectiva, esse instrumento conceitual (mais que método) que tantas soluções trouxe para os artistas no tempo de sua descoberta. Mas o sucesso da perspectiva terminou por criar uma crosta sobre a concepção de arte, de modo que, quando outras soluções para os problemas da arte foram trazidas em fins do século XVIII e no século XIX, inevitáveis embaraços grassaram a recepção de grandes artistas inovadores. Atados àquela concepção de real (e de arte como a imitação desse real), os contemporâneos do Impressionismo, por exemplo, não souberam, de imediato, reconhecer sua grandeza. O Impressionismo (com sua exigência de pintar paisagens em sua própria luz) mostrou que não era verdade que víamos as coisas tais como a ilusão da perspectiva nos acostumara a ver. Assim, aquilo que para os primeiros apreciadores de Monet, por exemplo, era simples mancha suja sobre a tela (numa demonstração de desperdício de tinta) depois se revelou, na dimensão da história da arte, uma impressionante forma de reaprender a ver o mundo. A dificuldade para esses primeiros receptores do Impressionismo (mas também para muitos de nossos jovens de todas as idades, que são também nossos antigos de todas as épocas) não estava apenas no apego a certa concepção de grande arte, mas também no apego àquela concepção de real (KLEIN, 1998, p. 227) como o ser percebido.

Isto não quer dizer, todavia, que seria o Impressionismo, sozinho, o movimento que transtornaria a relação entre arte e percepção, já que duas de suas notáveis características (o apego à luz natural e o não abrir mão do modelo) não deixaram de ser um reforço para a conquista de uma possível verdade que, como a perspectiva, se antepunha entre o artista e a obra (GOMBRICH, 1999, p. 519-536). Seria preciso esperar pelo século

\begin{tabular}{|c|c|c|c|c|}
\hline Ronista Dialectus & Ano 9 & n. 17 & Maio - Agosto 2020 & p.137-151 \\
\hline
\end{tabular}


XX e seus teóricos e pensadores, para que o revertério da noção de realidade implicasse numa nova atitude em face da obra de arte. A arte em geral e a literatura em particular, desde Aristóteles (e, mesmo, Platão), de qualquer modo, reconheciam-se pela operação da mímesis, que os latinos traduziriam, como dissemos, por imitatio, a nossa "imitação". Daí a supor que o real seja um modelo, e o produto da mímesis (a obra de arte), sua cópia, não há qualquer distância. Se a grande arte era aquela que "imitava" bem o que percebíamos como real, então qualquer atropelo nessa relação entre o imaginário da criação e o real anteposto levaria a arte para a categoria da má realização e do erro, quando não da falta de decoro (LIMA, 1988). Mas esta linearidade (da arte ao real), a ser desfeita, pouco esconde a tremenda simplificação, ou falsificação, à espreita do problema que esse tipo de relação sempre põe.

Para entendermos o que acaba de ser dito, recordemos o seguinte movimento de pensar, próprio de Luiz Costa Lima, antes mencionado: se uma concepção de real controlava (LIMA, 1989, p. 11-69), de longe, mas incisivamente, o que poderia ou não ser considerado arte, de duas uma: ou se abandonaria o recurso à mímesis, ou se enfrentaria a tarefa de uma sua nova teorização. Os românticos alemães foram os primeiros a se revoltarem contra a tacanha estreiteza daquela concepção tradicional da relação da arte com a realidade, e relegaram a mímesis (sempre mal compreendida como imitatio) para o escanteio próprio das quinquilharias abomináveis ao gênio criador. A arte se via, desse modo, livre da obrigação de imitar um real preexistente, mas os teóricos da arte, com isso, também se livravam da tarefa de pensar aquele real de que a arte supunha livrar-se. E nisso foram herdeiras as vanguardas do século XX, nisto de relegar a mímesis mal assimilada (não teorizada), como também na ênfase, correspondente, da absoluta liberdade da criação artística (graças ao conceito fíchteano de "ironia", reinterpretado por F. Schlegel $<$ Hegel, 2001, p. 81ss>), como obra de gênio que a si mesmo, como diria Kant, dá suas regras (KANK, 1993, p. 153ss; Suzuki, 1998, passim), e concebe a natureza como coisa posta, e não mais como modelo prévio a dominar por fora o ato criativo (LIMA,1986). Mas nesse caso pode-se, com acerto, dizer que aqueles teóricos jogaram fora a questão da mímesis antes de a resolverem, pois desdenhar dela como mera imitação para livrar a arte da tutela

\begin{tabular}{|c|c|c|c|c|}
\hline Ronista Dialectus & Ano 9 & n. 17 & Maio - Agosto 2020 & p.137-151 \\
\hline
\end{tabular}


do real (naturalizado) não é, já, desfazer-se do conceito de real como estabilidade posta, porém até mesmo aceitá-lo sem discussão (LIMA, 1989, p. 72ss): o que talvez tenha sido mais uma atitude dos herdeiros vanguardistas do que dos legatários românticos.

Quanto à implosão de certa concepção de real, necessária, ao lado de uma crítica do conceito de subjetividade, para o revigoramento da concepção de mímesis, o próprio Platão, quando considera o assunto das relações entre arte e realidade, por volta do final do livro II e do começo do livro III de A república, ao questionar a mímesis, deixa entrever uma posição para a qual é também cabível certo questionamento. Ao contrário dos artistas pós-românticos, porém, Platão não despreza a mímesis em favor da arte livre, mas questiona tanto a realidade quanto a própria arte, em favor de um ideal superior, ou de uma concepção superior de realidade, a saber: a cidade que ele constrói através do diálogo traçado entre Sócrates, Glauco, Adimanto, etc. O questionamento platônico da realidade se deixa ver na própria execução do diálogo como construção de uma cidade ideal. Projetar uma cidade ideal não seria dizer, a contrapelo, que a cidade real não prestaria? Procurar a justiça e o bem alhures, não seria dizer que, aqui e agora, o que se vê não passaria de injustiça e corrupção? Essa dimensão não devia ser negligenciada durante a leitura do filósofo. Quanto à arte, o seu problema, para Platão, não é que ela represente em geral, mas que represente também a corrupção e a injustiça, a intemperança e a indignidade, como o fazem Homero e Hesíodo ao falarem “dos deuses, das divindades, dos heróis e das coisas do Hades" (PLATÃO, 2001, p. 329a-e). Um exame mais detido da passagem acima referida contrasta com a ideia generalizada de que Platão teria rejeitado a mímesis. Senão, vejamos.

De partida, que se leia o trecho inicial da passagem a que estamos nos referindo:

A maior das mentiras e acerca dos seres mais elevados, que foi feita sem nobreza, é que Uranos tenha tido o procedimento que Hesiodo lhe atribui, e depois como Cronos se vingou dele. E os atos de Cronos e o que sofreu por parte do filho [Zeus], ainda que supuséssemos ser verdade, não deviam contar-se assim descuidadamente (id., ibid.: 378a),

\begin{tabular}{|c|c|c|c|c|}
\hline Ronista Dialectus & Ano 9 & n. 17 & Maio - Agosto 2020 & p.137-151 \\
\hline
\end{tabular}


principalmente quando se sabe que é às criancinhas que tais coisas são contadas. A certeza previamente compartilhada de que o efeito da arte sobre a educação dos jovens é tremendo e eficaz, e não uma desconfiança qualquer sobre o poder artístico (a techné da mímesis), move o filósofo na direção de legislar a respeito da mímesis e dizer que coisas terríveis como as supostamente cometidas pelos deuses não podem ser narradas (para qualquer um). Do mesmo modo, jamais é questionada a certeza previamente compartilhada de que, se queremos uma cidade justa, é pela educação das crianças no sentido da justiça que alcançaremos esse objetivo. Platão fala de "inclinar os jovens" (390a), depois de “convencer" (391e) e, por fim, "modelar" (400e). Não se pode, pois, ao que parece, prescindir nem da arte nem da educação. Mas a educação, que inclina, convence e, por fim, modela, não seria também ela uma forma de mímesis?

A educação, de qualquer modo, é seletiva: educa-se num caminho e não em outro; educa-se para a injustiça ou para a justiça, mas jamais para ambas ao mesmo tempo. A arte, em contrapartida, é não-seletiva (não valora), na acepção de que representa tanto o bem quanto o mal, e ambos na maior perfeição. "Quem quiser ser um criador no bem e no mal, deve primeiro ser um exterminador e romper valores. Assim, o mal supremo pertence ao mais elevado bem: mas este é o criador", escreve o maior dos antiplatônicos: Nietzsche. Por isso, quando o assunto de base é a educação, que forma valores (e não a arte, que explode valores), faz-se preciso escolher, na arte, o que dela pode ser aproveitado para a realização do projeto educativo em foco. Mas, se a arte, ou mais precisamente, a mímesis entendida como poder artístico, é não-seletiva, se ela está aquém do bem e do mal e, por isso, pode produzir tanto o bem quanto o mal, tanto a desonra quanto "a firmeza e o bom senso" (PLATÃO, 2001, p. 396e), ao filósofo-educador, que a reconhece como tal na medida em que elenca o que dela deve ser deixado de fora e o que dela deve entrar e permanecer na cidade, só lhe resta manter-se em alerta, escrutinando cada produto dela, sopesando-o a fim de que se possa estar certo da dignidade do que se apresenta como produto de arte, isto é, como material pedagógico para a formação do cidadão. Dir-se-ia que a educação é artificial, ao passo que a mímesis seria natural?

\begin{tabular}{|l|l|l|l|l|}
\hline Qovista Dialectus & Ano 9 & n. 17 & Maio - Agosto 2020 & p.137-151 \\
\hline
\end{tabular}


É este o ponto em que queríamos chegar. Sem ter o que fazer com os poetas que aportem à sua cidade, além de cobrir-lhes de honrarias, como a deuses (id., ibid., p. 398a), para em seguida convidar-lhes delicadamente a irem embora, deixando ficar apenas "um poeta e um narrador de histórias mais austero e menos aprazível, tendo em vista a sua utilidade, a fim de que ele imite para nós a fala do homem de bem e se exprima segundo aquele modelo que antes regulamos" (398a-b), o filósofo-educador, que receia todo tipo de erro e detesta ser enganado, o que significa, também, que tem uma espécie de horror à multiplicidade e à metamorfose, e um amor delicado ao simples, aponta, todavia, embora sem ostentação, para aquilo mesmo que ele quer ocultar, e que caberá a Aristóteles explicitar.

Há, com efeito, em Aristóteles, dois momentos nos quais aparece e se mostra a fonte do "erro" que é também, como gostaria de mostrar, a fonte da verdade. Um, na Poética, que examinaremos diretamente. Outro, em De anima, que examinaremos seguindo a leitura que Castoriadis faz do texto. Na Poética, podemos ler a seguinte passagem muito significativa:

Duas causas, ambas naturais, parecem ter dado origem (genesai) à arte poética como um todo. De fato a ação de mimetizar se constitui nos homens desde a infância (ék paidon), e eles se distinguem das outras criaturas (zoom, animais) porque são os mais miméticos e porque recorrem à mimese para efetuar suas primeiras formas de aprendizagem, e todos se comprazem com as mimeses realizadas (ARISTÓTELES, 2017, p. 57).

Ao lermos isso, tendo acabado de reler as páginas de Platão sobre Sócrates e sua tentativa de fazer uma cidade perfeita, é muito difícil não constatar que Sócrates, que sabia de ambas as coisas, ou seja, de que o imitar é congênito ao ser humano (ék paidon), e de que os seres humanos se comprazem (kairein) com o imitado, tenha sido desonesto quando, sob a mão de Platão, forçou a situação para que esqueçamos dessa natureza imitativa do ser humano, desse diferencial do ser humano em relação aos outros animais, e, procurando a todo o custo a austeridade, fez tábua rasa da evidência de que nos deleitamos com as coisas imitadas. Aristóteles, ao invés, revela tudo: não se pode deixar de imitar, já que ser humano implica esse tipo de ação; mas também não se pode, senão mediante um

\begin{tabular}{|c|c|c|c|c|}
\hline Ronista Dialectus & Ano 9 & n. 17 & Maio - Agosto 2020 & p.137-151 \\
\hline
\end{tabular}


ato consciente de inclinação, de modelagem, de convencimento, conduzir quem experimenta da mímesis e de seus efeitos a um contato meramente austero, sem prazer, porque o prazer, segundo Aristóteles, de uma forma ou de outra sempre está em jogo no momento da apreciação.

A singela desonestidade de Sócrates, porém, é do tamanho de sua grandeza humana. Sua e de Platão. Pois, se eles torcem a realidade das coisas, como o fazem todos os ideólogos, não o fazem, todavia, em nome do real existente, mas em vista de uma cidade ideal. Platão, ao construir seu Sócrates produtor de cidade ideal, é um ideólogo, sim, mas ideólogo de uma cidade não-existente. O que faz toda a diferença, já que o poder que ele defende, uma vez que todo ideólogo defende um poder, é um que só existe na própria plástica de sua... não podemos dizer simplesmente "narração", já que $A$ república não é somente uma narração, mas também, como a tragédia, um diálogo, logo, uma arte imitativa, segundo sua própria definição de "imitação" como discurso direto, que nos faz acreditar que é Glauco mesmo quem fala, Glauco, Trasímaco e Adimanto, além do próprio Sócrates, claro. Aristóteles, ao contrário, ao dizer que a imitação é congênita ao homem, não fala como ideólogo, mas como quem descreve uma realidade de que não se pode eludir. Fala, portanto, como filósofo: ele olha o que é e diz o que, ao olhar, ele vê. Mas, o que vê Aristóteles, quando vê que a "imitação" (a mímesis) é congênita ao ser humano?

Segundo Hans Blumenberg, Aristóteles vê a resposta à seguinte questão: "o que o homem poderia produzir no mundo e do mundo, por sua força e destreza?” (Blumenberg, 2010, p. 87). A resposta: o homem pode produzir arte (tékhne). Mas o que vem a ser tékhné? Tékhné é mímesis da phusis: "arte é imitação da natureza." Que a arte imite a natureza, porém, e foi isso o que não viram os latinos que, já tendo traduzido phusis por natura, traduziram mímesis por imitatio, isso não quer dizer que a arte tome o que a natureza oferece em sua exuberância sensível (a natura naturata) e a reproduza, em uma cópia; isto quer dizer, antes, que, se a natureza dá (se ela é uma natura naturans, isto é, uma força ativa, produtiva), a arte também pode oferecer: quer dizer, a arte pode gerar, ou para aperfeiçoar o que a natureza apenas começou (é a técnica do artesanato), ou para pôr o que ela jamais produziu (é a arte propriamente dita como imitação da natureza, isto é, como

\begin{tabular}{|l|l|l|l|l|}
\hline Qovista Dialectus & Ano 9 & n. 17 & Maio - Agosto 2020 & p.137-151 \\
\hline
\end{tabular}


um fazer também), mas sempre de uma forma tal que, se a natureza intentasse fazer, faria igualmente, embora à sua maneira.

Mas Aristóteles diz algo mais, além disso. Ele diz, contrariando Platão que queria uma arte que fosse somente austera, que "os homens se comprazem no imitado." Comprazer-se possui dois sentidos: alegrar-se, bem entendido; mas também: alegrar-se “com”, festejar. A festa é, etnologicamente concebida, uma manifestação coletiva. Ao aproximar a mímesis do comprazimento, sem dúvida Aristóteles deixa escapar a reminiscência da própria origem da palavra que, segundo alguns, está ligada ao culto de Baco. "Mimos", escreve Costa Lima, segundando Koller, "é originalmente o ator da dança do culto a Baco e mímesis, a dança pela qual a 'cura' se realizava” (LIMA, 1980, p.31). A palavra "cura" traduz, aqui, catharsis, a purificação que educa. Aristóteles não está menos preocupado que Platão quanto ao ato de aprender, o que muda aqui é somente a pedagogia: segundo ele - e é o que fica claro na passagem citada acima - o prazer não está de fora do ato da aprendizagem, e esta ocorre na companhia dos outros (dos mais velhos). Alegrandose, deleitando-se com o modo como os mais velhos fazem o que tem de ser feito (o culto, por exemplo), os jovens vão lá, na festa, e fazem o mesmo.

A referência a essa dimensão coletiva, social, da mímesis como locus da aprendizagem é de suma importância. "O produto mimético é um dos modos de estabelecimento da identidade social" (LIMA, 1980, p. 24). Identidade social, aqui, precisa ser entendida, porém, em dois sentidos: o de reconhecimento, ao lado de outros membros do grupo, da semelhança que a obra mimética desperta em relação ao já conhecido; o de coesão dos laços desses mesmos membros que, no ato do reconhecimento da semelhança, veem-se a si mesmos como iguais. Aristóteles, com efeito, enfatiza essa dupla dimensão quando escreve: "Prova disso", a saber, do comprazimento com o imitado, o mimetizado, "é o que ocorre na prática: com efeito, quando observamos situações dolorosas, em suas imagens mais depuradas, sentimos prazer ao contemplá-las; por exemplo, diante das formas dos animais mais ignóbeis e dos cadáveres. A causa disso é que conhecer apraz não apenas aos filósofos, mas, de modo semelhante, também aos outros homens." E continua: "Pois sentem prazer ao observar as imagens e, uma vez reunidos, aprendem a contemplar e a

\begin{tabular}{|l|l|l|l|l|}
\hline Qovista 2 ialectus & Ano 9 & n. 17 & Maio - Agosto 2020 & p.137-151 \\
\hline
\end{tabular}


elaborar raciocínios sobre o que é cada coisa, e dirão, por exemplo, que este é tal como aquele" (ARISTÓTELES, 2017, p. 57). Diante disso, e graças à ênfase em "uma vez reunidos", Castoriadis não hesitará em ajustar o ato criador do ser humano (a tékhne como mímesis da phusis) à constituição do ser social-histórico.

O ser social-histórico é o lugar de passagem do reconhecimento da coisa na imagem por um membro de um grupo ao compartilhamento desse reconhecimento com os outros membros. Para compreender isso, todavia, é preciso entender que a mente (a psique, a alma) que age nesse evento não é uma faculdade desde sempre individual. O prazer individual do reconhecimento está intimamente relacionado com a oportunidade do compartilhamento porque, na verdade, trata-se de um único e mesmo acontecimento: o pensar começa com a tribo, e só por um processo de desenvolvimento muito lento é que vêm a se identificar com um ato individual não só os conteúdos desse pensar (os noemas que são, antes de tudo, mitemas, conforme nos lembraria Cassirer <2004>) interiorizados pelo membro, mas a própria atividade pensante (a noésis), mais tarde a principal atividade de um certo indivíduo chamado "o filósofo".

Essa gênese social antes que individual do ato de pensar, na medida em que ela é, enquanto gênese, produtora de imagens míticas, logo, poder de criação (tékhne como mímesis da phusis, desde a origem), marca a proximidade de princípio, antes que ruptura, entre o logos e o muthos, o pensamento e a fantasia. E é o próprio Aristóteles quem reconhece isso. Castoriadis cita o De anima: "Para a alma pensante, as fantasias são como sensações. É por isso que a alma jamais pensa sem fantasia" (CASTORIADIS, 2002, p. 352). Essa é a segunda passagem que cobra nosso comentário.

Como dissemos, nós o faremos acompanhando Castoriadis. E o que primeiro chama a atenção do autor de As encruzilhadas do labirinto é a "oscilação do sensível e do inteligível" (id., ibid., p. 253), passível de ser depreendida naquele trecho aristotélico. Castoriadis, todavia, não o comenta em vista de demarcar o lugar da mímesis, senão que em vista de apontar o local de nascimento da imaginação (fantasia). Todavia, parece ser possível reencontrar a ambiguidade platônica da mímesis quando recuperarmos o significativo saldo do comentário de Castoriadis. Segundo ele, há duas concepções de

\begin{tabular}{|l|l|l|l|l|}
\hline Qovista 2 ialectus & Ano 9 & n. 17 & Maio - Agosto 2020 & p.137-151 \\
\hline
\end{tabular}


fantasia, em Aristóteles: uma, a que ficou mais conhecida, que ele chama de "imaginação segunda" (id., ibid., p. 355), que Aristóteles descreve como "movimento engendrado por uma sensação em ato" (id., ibid., p. 355); a outra, que foi deixada de lado, inclusive pelo próprio Aristóteles que a formulou, a qual Castoriadis quer chamar de "imaginação primeira", e que é a fonte de (mas que aparece como "um Terceiro" entre) a sensação e a intelecção, que escapa a essa divisão “e põe em causa seu fundamento" (Id., ibid., p. 355). Pôr em causa o fundamento da distinção tradicional entre o sensível e o inteligível significa, para ele, constatar que esse Terceiro não é um elemento que teria ficado de fora desse par, e que surgisse no meio de suas tensões vindo de um exterior qualquer. "Ele age no e a partir do interior dessa divisão, e parece torná-la impossível, já que esse Terceiro se encontra às vezes no Um e às vezes no Outro, sem ser Um ou Outro" (Id., ibid., p. 355). Ora, a partir disso, parece possível reencontrar a análise, feita acima, de Platão. Aquilo para o que Platão aponta ao se precaver contra, tentando regular seus produtos, não seria isso mesmo que Castoriadis descreve, lendo Aristóteles, como esse "ser-não-ser: a fantasia” (id., ibid., p.. 355)? Dá para sentir de longe o drama de Platão, quando (1) ele insiste que o Deus só pode produzir o que é bom, ficando reservado o mal para ser efeito de outra causa que não a divina, jogando fora, com isso, um terço das representações advindas da poesia grega; quando (2) prova que não é digno de um Deus se metamorfosear, devendo ser sempre algo simples, jogando fora outro terço daquela mesma poesia; quando (3) deixa claro que ninguém aceita ser enganado, consumando sua vitória (a vitória da filosofia) sobre a herança poética; quando, enfim, (4) elabora um modelo conveniente de lançar mão da mímesis sem se deixar contaminar com seu poder de feitiço e de multiplicação tanto do bem quanto do mal, tanto do aceitável quanto do horripilante. Porque o próprio Platão é um criador e precisa, como dizia Nietzsche, exterminar e romper valores, como os da epopeia, da tragédia e mesmo da sofística. Mas Platão sabe que não pode competir com esse "sernão-ser", que nasce e renasce como uma hidra cortada, e é por isso que os poetas têm de ficar de fora da cidade (como os sofistas hão de ficar de fora da filosofia), cabendo nela apenas os poetas medíocres (“austeros", diria Platão), que podem ser controlados com facilidade, e trazidos para a tarefa de educar os guerreiros.

\begin{tabular}{|l|l|l|l|l|}
\hline Qovista Dialectus & Ano 9 & n. 17 & Maio - Agosto 2020 & p.137-151 \\
\hline
\end{tabular}


A arte da educação, que seria esse processo de passagem do sensível ao inteligível, por cima daquele "Terceiro" de Castoriadis, que ficaria recalcado, enterrado, "esquecido", seria a obra da segunda imaginação que, como foi dito antes, seleciona, valora, orienta-distorce. A arte propriamente poética seria a obra da imaginação primeira, essa fantasia sem a qual não se pode pensar, que é como sensação sem ser sensação, porque é inteligível, e é inteligível sem ser inteligível porque é como sensação. Ela é "como o sensível", "mas sem matéria" (id., ibid.: 354); o que é o mesmo dizer: ela é qualquer coisa de absolutamente livre, qualquer coisa impassível de ser fisgada, controlada, esgotada. Qualquer coisa que não é, afinal, uma "coisa": Póiesis, dirá Castoriadis, depois de Merleau-Ponty (1999) chamá-la de "quiasma", ser bruto ou ser selvagem.

Ora, essa menção ao selvagem vem a calhar. A oposição traçada acima entre educação e arte poiética (tékhne como mímesis da phusis, seja como artesanato, seja como obra de arte; numa palavra: trabalho) não poderia ela recobrir a oposição entre processo civilizatório e barbárie? A resposta a essa pergunta algo ousada só poderia ser positiva se passássemos por uma séria revisão não só semântica no quesito de nossas valorações acerca do que seja civilizado e do que seja selvagem, bruto, bárbaro. Se continuarmos a pensar que o civilizado é o racional e polido e o bárbaro é o irracional e violento, não andaremos um passo. Melhor seria pensar que há uma violência na polidez (aquela inscrita no inclinar e moldar dos atos educativos) como há uma violência na barbaridade (a irrupção sempre pronta a transbordar em atos e obras de transvaloração dos valores, todavia também sempre recalcada pelo processo civilizatório).

Para ajustar essa questão ao problema da mímesis, que nos seja permitido evocar aqui, rapidamente, um texto de Theodor Adorno, do final de sua Teoria estética. Sob a rubrica "Teorias sobre a origem da arte", Adorno examina criticamente as variadas e contrapostas tentativas de pensar a pré-história da arte. Sem aderir a nenhuma delas, o que lhe importa enfatizar é a própria multiplicidade dessas tentativas, que apontaria, por choque em retorno, para a rebeldia originária do que se tenta domar mediante o encontro com "a fonte", a "origem" que lhe conformaria o conceito. "O que parece tornar-se indistinto na penumbra da pré-história", ele escreve, "é vago não por causa do seu afastamento, mas

\begin{tabular}{|l|l|l|l|l|}
\hline Qovista Dialectus & Ano 9 & n. 17 & Maio - Agosto 2020 & p.137-151 \\
\hline
\end{tabular}


porque assim se encontra salvaguardado algo desse vago inadequado ao conceito, cuja integração constante ameaça incansavelmente a sua existência” (ADORNO, 1982, p. 359). O que acima, para caracterizar a mímesis como imaginação primeira, foi chamado de "sernão-ser" solidariza-se com a preservação dessa atitude avessa à terminologia apropriadora, bem do conceito, atitude que defende o indeterminado contra as garras da reificação, da transformação em coisa daquilo que não é nem pode ser "uma coisa", segundo a compreensão corrente que se tem de coisa como algo palpável, tangível e, nessa medida, dominável.

Aquele "indeterminado" é o que Adorno, recuando da mais antiga arte do paleolítico, chama de "comportamento mimético", a "imitação da natureza" anterior à produção da obra de arte, inscrito já no corpo do ser humano selvagem que se protege das intempéries naturais repetindo seus movimentos, e que não é exclusividade desse homem que nossa consciência burguesa gostaria de chamar "primitivo" em contraposição à nossa própria autoconsciência de seres civilizados, “evoluídos”! O comportamento mimético é tão racional quanto não-racional; é a fonte tanto de nossa produção de conceitos quanto de nossa produção de fantasias; tanto da educação quanto da arte. Esteve disponível ao homem primitivo e está disponível ao homem contemporâneo. Apenas a "sabedoria do filisteu, que separa o sentimento e o entendimento e se alegra quando encontra os dois em equilíbrio, é, como certas trivialidades, a caricatura do estado de coisas que, no decurso de milênios de divisão do trabalho, inscreveu esta divisão na subjetividade" (id., ibid., p. 364), e por isto nos leva a pensar que recalcar a fonte pelos procedimentos da repressão psíquica que Freud chamaria de "sublimação" poderia manter viva a divisão do trabalho (entre a mão e o intelecto) que só interessa ao filisteu.

Resta, por fim, uma última imagem: enquanto a educação é um tear de fios grossos a compor um tampo que dissimule a origem bárbara sempre preste a irromper no presente, e compô-lo a fim de manter e prolongar a ordem existente, a arte é um tear de finos fios a manufaturar um véu que cobre a mesma fonte, mas um véu de cujas frestas pode-se ver, por todos os lados, aquilo de onde ela brota ao inventar seus mundos, e de onde muitos outros mundos virtuais ainda podem ser inventados, atualizados. Platão, por

\begin{tabular}{|l|l|l|l|l|}
\hline Qovista 2 ialectus & Ano 9 & n. 17 & Maio - Agosto 2020 & p.137-151 \\
\hline
\end{tabular}


exemplo, que viu de perto essa fonte, dissimulou o quanto pôde o seu contato com ela. Mas, na medida em que esse contato fora efetivo, criou um mundo todo dele, onde o primado da ciência sobre a arte e a poesia não é assegurado senão a custa da grande força poética posta a trabalhar nas nervuras que sustentam a arte literária de seus diálogos maravilhosos.

\section{Referências:}

ADORNO, TH. Teoria estética. Trad.: A. Morão. Lisboa: Edições 70, 1982.

ARISTÓTELES. Poética. Trad.: Eudoro de Souza. São Paulo: Nova Cultural, 1991.

BLUMENBERG, H. "Imitação da natureza": contribuição à pré-história do homem criador (1957), in: LIMA, L. C. (Org.) Mímesis e a reflexão contemporânea. Rio de Janeiro: EDUERJ, 2010.

CASSIRER, E. A filosofia das formas simbólicas. II. O pensamento mítico. Trad.: C. Cavalcante. São Paulo: Martins Fontes, 2004.

CASTORIADIS, C. As encruzilhadas do labirinto, 2. Os domínios do homem. Trad.: J. O. de A. Marques. Rio de Janeiro: Paz \& Terra, 2002.

DANTO, A. O descredenciamento filosófico da arte. Trad.: R. Duarte. Belo Horizonte: Autêntica, 2014.

GAGNEBIN, J.-M. Do conceito de mímesis no pensamento de Adorno e Benjamin”, in: Sete aulas sobre linguagem, memória e história. Rio de Janeiro: Imago, 1997.

GOMBRICH, E. H. A história da arte. Trad.: A. Cabral. Rio de Janeiro: LTC, 2009.

HEGEL, G. W. F. Curso de estética I. Trad.: M. A. Werle. São Paulo: Edusp, 2001. KANT, I. Crítica da faculdade do juízo. Trad.: V. Rohden e A. Marques. Rio de Janeiro: Forense, 1993.

KLEIN, R. Pompônio Gaurico e seu capítulo 'Da perspectiva', in: A forma e o inteligível. São Paulo: Edusp, 1998.

LIMA, L. C. Mímesis e modernidade. Formas das sombras. Rio de Janeiro: Graal, 1980.

\begin{tabular}{|l|l|l|l|l|}
\hline Qovista Dialectus & Ano 9 & n. 17 & Maio - Agosto 2020 & p.137-151 \\
\hline
\end{tabular}


O controle do imaginário. Rio de Janeiro: Forense, 1989.

. O fingidor e o censor. No ancien regime, no iluminismo e hoje. Rio de Janeiro: Forense, 1988.

. Um conceito proscrito: mimese e pensamento de vanguarda, in: Sociedade e discurso ficcional. Rio de Janeiro: Guanabara, 1986.

MERLEAU-PONTY, M. O visível e o invisível. Trad.: J. A. Giannotti e A. M. D’Oliveira. São Paulo: Perspectiva, 1999.

NIETZSCHE, F. Assim falou Zaratustra. Trad.: P. C. De Souza. São Paulo: Companhia das Letras, 2011.

PLATÃO. A República. Lisboa: Calouste Gulbenkian, 2001.

\begin{tabular}{|l|l|l|l|l|}
\hline Qovista 2 ialeatus & Ano 9 & n. 17 & Maio - Agosto 2020 & p.137-151 \\
\hline
\end{tabular}

